\title{
Morfologia fenotípica de Bixa arborea e Bixa orellana (Bixaceae) em Alta Floresta, Mato Grosso, Brasil
}

\author{
Phenotypic morphology of Bixa arborea and Bixa orellana (Bixaceae) in Alta Floresta, Mato \\ Grosso, Brazil \\ Morfología fenotípica de Bixa arborea y Bixa orellana (Bixaceae) en Alta Floresta, Mato Grosso, \\ Brasil
}

Recebido: 29/06/2021 | Revisado: 05/07/2021 | Aceito: 07/07/2021 | Publicado: 17/07/2021

\author{
Thatielen Furini \\ ORCID: https://orcid.org/0000-0003-3420-1639 \\ Universidade do Estado do Mato Grosso, Brasil \\ E-mail: thatyfurini2003@hotmail.com \\ Isane Vera Karsburg \\ ORCID: https://orcid.org/0000-0002-9637-0449 \\ Universidade do Estado do Mato Grosso, Brasil \\ E-mail: isane9@gmail.com \\ José Martins Fernandes \\ ORCID: https://orcid.org/0000-0002-8264-5085 \\ Universidade do Estado do Mato Grosso, Brasil \\ E-mail: fernanbio@bol.com.br \\ Samiele Camargo de Oliveira Domingues \\ ORCID: https://orcid.org/0000-0002-7772-8310 \\ Universidade do Estado do Mato Grosso, Brasil \\ E-mail: samieledomingues@gmail.com \\ Joelson de Oliveira Barros \\ ORCID: https://orcid.org/0000-0003-2348-8590 \\ Universidade do Estado do Mato Grosso, Brasil \\ E-mail: joel_bio10@hotmail.com \\ João Paulo Medeiros Schmitt \\ ORCID: https://orcid.org/0000-0002-4424-8564 \\ Universidade do Estado do Mato Grosso, Brasil \\ E-mail: joaopaulomedeirossschimitt@gmail.com \\ Edmar Santos Moreira \\ ORCID: https://orcid.org/0000-0001-6493-3975 \\ Universidade do Estado do Mato Grosso, Brasil \\ E-mail: edmar.moreira@unemat.br \\ Luiz Fernando Scatola \\ ORCID: https://orcid.org/0000-0001-9329-8317 \\ Universidade do Estado do Mato Grosso, Brasil \\ E-mail: luiz.scatola@unemat.br
}

\begin{abstract}
Resumo
Bixa arborea e Bixa orellana, são duas espécies vegetais da família Bixaceae, com ampla distribuição na América do Sul e largamente usada pela população tradicional. As espécies do gênero Bixa apresentam um pigmento avermelhado nas sementes, que vem sendo utilizado pelas populações nativas por muito tempo. Os compostos fitoquímicos presentes nas sementes de Bixa orellana também são muito utilizados na indústria alimentícia e têxtil (como corante). Bixa arborea além do uso fitoterápico das folhas, também é muito empregada na restauração florestal e como fonte de madeira. Nesse contexto, é de extrema importância diferenciar B. arborea de B. orellana por meio de diagnoses morfológicas para compreender melhor os caracteres que separam as duas espécies. Também buscou analisar as diferenças morfológicas existentes entre os espécimes de B. arborea, para avaliar a existência de híbridos na população analisada. Para isso, foi realizado diagnoses morfológicas para as duas espécies. A partir disso, foi possível perceber que as duas espécies apresentam muitas semelhanças morfológicas, diferindo basicamente uma da outra pelo aspecto do fruto: $B$. arborea apresentou frutos papilosos ou parcialmente cobertos por espinhos não flexíveis com comprimento variando de 0,1-1,8 mm, enquanto $B$. orellana apresenta frutos totalmente cobertos por espinhos flexíveis e com comprimento variando de 4 a $9,6 \mathrm{~mm}$. A quantidade média de sementes nos frutos de com $B$. orellana foi maior que o encontrado nos frutos de B. arborea. Portanto, nosso trabalho mostrou que as duas espécies apresentam diferenças fenotípicas, as quais podem ser utilizadas na identificação e diferenciação uma da outra.
\end{abstract}

Palavras-chave: Caracteres morfoagronômicos; Colorau; Urucum. 


\begin{abstract}
Bixa arborea and Bixa orellana, are two plant species of the Bixaceae family, with wide distribution in South America, and widely used by the traditional population. The species of the genus Bixa have a red to reddish pigment in the seeds, which has been used by native populations for a long time. The phytochemicals present in the seeds of Bixa orellana are also widely used in the food and textile industry (as a dye). Bixa arborea, in addition to the phytotherapic use of leaves, is also widely used in forest restoration and as a source of wood. In this context, it is extremely important to differentiate $B$. arborea from $B$. orellana by means of morphological diagnoses to better understand the characters that separate the two species. It also sought to analyze the morphological differences between $B$. arborea specimens, to assess the existence of hybrids in the analyzed population. For this, morphological diagnoses were carried out for both species. From this, it was possible to notice that the two species have many morphological similarities, differing basically from each other by the aspect of the fruit: $B$. arborea presented papulous fruits or partially covered by non-flexible spines with length ranging from 0.1-1.8 mm, while $B$. orellana presents fruits totally covered by flexible spines and with length varying from 4 to $9.6 \mathrm{~mm}$. The average amount of seeds in the fruits of $B$. orellana was higher than that found in the fruits of $B$. arborea. Therefore, our work showed that the two species show phenotypic differences, which can be used to identify and differentiate one from the other.
\end{abstract}

Keywords: Morpho-agronomic characters; Paprika; Annatto.

\title{
Resumen
}

Bixa arborea y Bixa orellana, son dos especies vegetales de la familia Bixaceae, con amplia distribución en América del Sur, y muy utilizadas por la población tradicional. Las especies del género Bixa tienen un pigmento de rojo a rojizo en las semillas, que ha sido utilizado por las poblaciones nativas durante mucho tiempo. Los fitoquímicos presentes en las semillas de Bixa orellana también se utilizan ampliamente en la industria alimentaria y textil (como colorante). Bixa arborea, además del uso fitoterápico de las hojas, también se utiliza mucho en la restauración forestal y como fuente de madera. En este contexto, es de suma importancia diferenciar B. arborea de B. orellana mediante diagnósticos morfológicos para comprender mejor los caracteres que separan a las dos especies. También se buscó analizar las diferencias morfológicas entre especímenes de $B$. arborea, para evaluar la existencia de híbridos en la población analizada. Para ello, se realizaron diagnósticos morfológicos para ambas especies. A partir de esto, se pudo notar que las dos especies tienen muchas similitudes morfológicas, diferenciándose básicamente entre sí por el aspecto del fruto: $B$. arborea presentó frutos papulosos o parcialmente cubiertos por espinas no flexibles con una longitud que varía entre 0.1-1.8 mm, mientras que $B$. orellana presenta frutos totalmente cubiertos por espinas flexibles y con longitud variable de 4 a $9,6 \mathrm{~mm}$. La cantidad promedio de semillas en los frutos de $B$. orellana fue mayor que la encontrada en los frutos de B. arborea. Por lo tanto, nuestro trabajo mostró que las dos especies presentan diferencias fenotípicas, que pueden usarse para identificar y diferenciar una de la otra.

Palabras clave: Personajes morfoagronómicos; Pimentón; Achiote.

\section{Introdução}

A família Bixaceae (Malvales) possui distribuição pantropical, representada por quatro gêneros e 21 espécies (APG, 2016; Stevens, 2021). É caracterizada pela presença de canais secretores; células não vasculares como acúmulo de resina; tricoma glandular e tricoma tector unicelular; folha alterna; inflorescência terminal; flor maior que 2,5 cm de diâmetro; parede celular anelar, desenvolvimento centrífugo, 5 ou 10 traços fasciculares; estigma ligeiramente lobulado; muitos óvulos por carpelo, micrópila em zigue-zague, funículo longo; cotilédone espatulado, curvado ou dobrado (Souza \& Lorenzi, 2019; Stevens, 2021).

No Brasil, a família está amplamente distribuída em todo o seu território, constituída pelos gêneros Bixa L. (B. arborea Huber, B. excelsa Gleason \& Krukoff, B. orellana L.) e Cochlospermum Kunth (C. orinocense (Kunth) Steud., C. regium (Mart. ex Schrank) Pilg. e C. vitifolium (Willd.) Spreng.), com total de seis espécies (Antar, 2020).

Bixa é nativo na América Tropical e possui cinco espécies, caracterizado como árvores; presença de flavonas, flavonóis, sulfatos de flavonoides e ausência de taninos não hidrolisáveis; pecíolo com feixe medular; cálice com nectários abaxiais emparelhadas, corola imbricada; anteras em forma de U invertido, com poros ou fendas medianas; gineceu 2-4 carpelos, oposto ao cálice, carpelos individuais inicialmente não visíveis, placentação parietal; tegumento externo do óvulo com 3-6 células, tegumento interno com 4-5 células, tecido parietal com cerca de 2 células, capa nucelar com cerca de 4 células de espessura; fruto suavemente espinhoso; testa polposa; $\mathrm{n}=7$ (Stevens, 2021).

A espécie Bixa orellana é muito utilizada pela população tradicional como fonte de pigmento vermelho (Alonso, 
2004). Esse pigmento é empregado na ornamentação do corpo pelos povos nativos da América e também comercialmente como fonte de corantes naturais utilizados pelas indústrias alimentícias, cosméticas e têxteis (Garcia et al., 2012; Mantovani et al., 2013; Demczuk \& Ribani, 2015; Rivera-Madrid et al., 2016; Sales et al., 2020; Izidoro et al., 2021). Além disso, $B$. arborea e $B$. orellana são empregadas na ornamentação, na restauração florestal, preparo de fitoterápico tradicional e na indústria farmacêutica (Lorenzi \& Matos, 2008; Pillai et al., 2018).

Diversas são as características químicas encontradas em $B$. arborea e $B$. orellana, que proporcionam o interesse da indústria (Garcia et al., 2012; Pillai et al., 2018). Atualmente, o corante produzido a partir das sementes de B. orellana é um dos mais utilizados em todo o mundo, uma vez que as sementes são ricas em carotenoides, bixinas e norbixinas, que garantem a cor avermelhada às sementes (Oliveira et al., 2005; Soares et al., 2011).

Embora a utilização de Bixa como fonte de pigmento não seja recente, uma vez que as populações nativas da América já utilizavam para ornamentação do corpo e utensílios, proteção contra picadas de insetos e como proteção solar, nas últimas décadas houve uma preferência pelos sintéticos (Corrêa \& Penna, 1984; Castro et al., 2009), gradualmente substituído por corantes naturais, novamente, a base de B. orellana (Mercadante et al., 1997). Atualmente, com a preferência por produtos naturais, o Brasil é um dos maiores produtores de corantes à base de Bixa, exportando para diversos países, só em 2017 o país produziu 13.363 toneladas de urucum, sendo o maior produtor mundial (Mercadante et al., 1997; IBGE, 2019).

A indústria alimentícia é o principal destino dos corantes produzidos a partir de B. orellana, onde é empregado para colorir queijos, manteigas e embutidos como salsichas (Moreira, 2013). Isso se deve principalmente porque o corante a base de urucum é um dos poucos permitidos pela Food and Agriculture Organization (FAO) (Moreira, 2013). Estudos têm mostrado ainda que os produtos à base de Bixa são ricos em compostos antioxidantes, usados em carnes e alimentos derivados (Garcia et al., 2012; Pillai et al., 2018). Dessa forma, os compostos antioxidantes podem diminuir a rancidez lipídica de produtos cárneos, como demonstrado por Garcia et al. (2012).

Além dos compostos químicos supracitados, as espécies de Bixa utilizadas como fonte de condimento, são ricas em vitaminas A e E (Oliveira et al., 2003), também são utilizadas como fitoterápico contra o câncer, contra doenças oportunistas decorrentes do HIV, como antibiótico e anti-inflamatório (Garcia et al., 2012; Rivera-Madrid et al., 2016). A presença de antioxidantes e carotenoides contribuem para bixina ser largamente utilizada na indústria farmacêutica e de cosméticos (Pillai et al., 2018).

As espécies de Bixa possuem uma ampla taxa de variedade genética (Dias et al., 2017). Dessa forma, estudos morfoagronômicos são necessários para conhecer a morfologia dos diferentes genótipos (Amaral, 2012). Além de permitir o entendimento de como os espécimes respondem à influência ambiental (Franco et al., 2002), inicialmente demonstrada pela morfologia.

A caracterização morfológica e agronômica dos diferentes genótipos de Bixa, também permite conhecer a diversidade genética e cria subsídios para estudos de melhoramento genético, facilitando a escolha de genótipos mais viáveis e com maior produtividade (Jesus et al., 2014; Ferraz et al., 2016). Uma das formas de realizar essa caracterização é através do estudo morfológico dos frutos e sementes, que é uma importante ferramenta para trabalhos de variabilidade genética de uma espécie, pois conhecer a variabilidade fenotípica facilita o processo de melhoramento genético (Fenner, 1993; Machado, 2015).

Pelo fato das espécies $B$. arborea e B. orellana apresentarem importância tradicional, comercial e na recuperação de áreas degradadas (Raddatz-Mota et al., 2017), justifica-se o desenvolvimento de estudos com a caracterização morfoagronômica e, posteriormente, o melhoramento genético de espécimes potenciais.

O trabalho tem como objetivo apresentar a morfologia de fenótipos de Bixa arborea e Bixa orellana (Bixaceae) no município de Alta Floresta, Mato Grosso, com chave para identificação, diagnoses morfológicas, ilustrações e contribuições da morfologia vegetal na distinção fenotípica. 


\section{Metodologia}

\section{1 Área de estudo e obtenção do material vegetal}

O município de Alta Floresta está localizado no extremo Norte do estado de Mato Grosso, Brasil (56 $05^{\prime} 10^{\prime \prime} \mathrm{W}$ e $09^{\circ}$ 52' 32" S), a $830 \mathrm{~km}$ da capital Cuiabá; apresenta um clima tropical quente úmido, com temperaturas médias elevadas (23 a $26^{\circ} \mathrm{C}$ ) durante o ano, com máximas diárias de 34 a $37^{\circ} \mathrm{C}$; os índices de pluviosidade anual acusam valores de 1.700 a $1.800 \mathrm{~mm}$ e ocorrem duas estações climáticas bem definidas - inverno seco e verão chuvoso (Zappi et al., 2011; PMAF, 2021).

A vegetação é formada predominantemente por Floresta ombrófila aberta e densa, Floresta estacional semidecidual e decidual e disjunções de cerrado (Zappi et al., 2011; PMAF, 2021). As principais atividades econômicas são prestação de serviços (turismo ecológico, lojas variadas, bares e restaurantes supermercados), agricultura, principalmente soja, milho e arroz e pecuária leiteira e de corte (IBGE, 2021; PMAF, 2021).

Os seis fenótipos de B. arborea foram coletados na propriedade de Terezinha Ruella de Oliveira (T.R.O), localizada na Estrada Vicinal $1^{a}$ Oeste, à $13 \mathrm{~km}$ da área urbana de Alta Floresta. O fenótipo de B. orellana foi coletado no Bairro Boa Esperança, rua Perimetral NW, $\mathrm{n}^{\circ}$ 1.300, no perímetro urbano de Alta Floresta (Figura 1). Os dois locais de coleta estão à uma distância aproximada de $5 \mathrm{~km}$.

Figura 1. Localização das áreas de coleta de Bixa arborea e Bixa orellana no município de Alta Floresta - MT, Brasil.

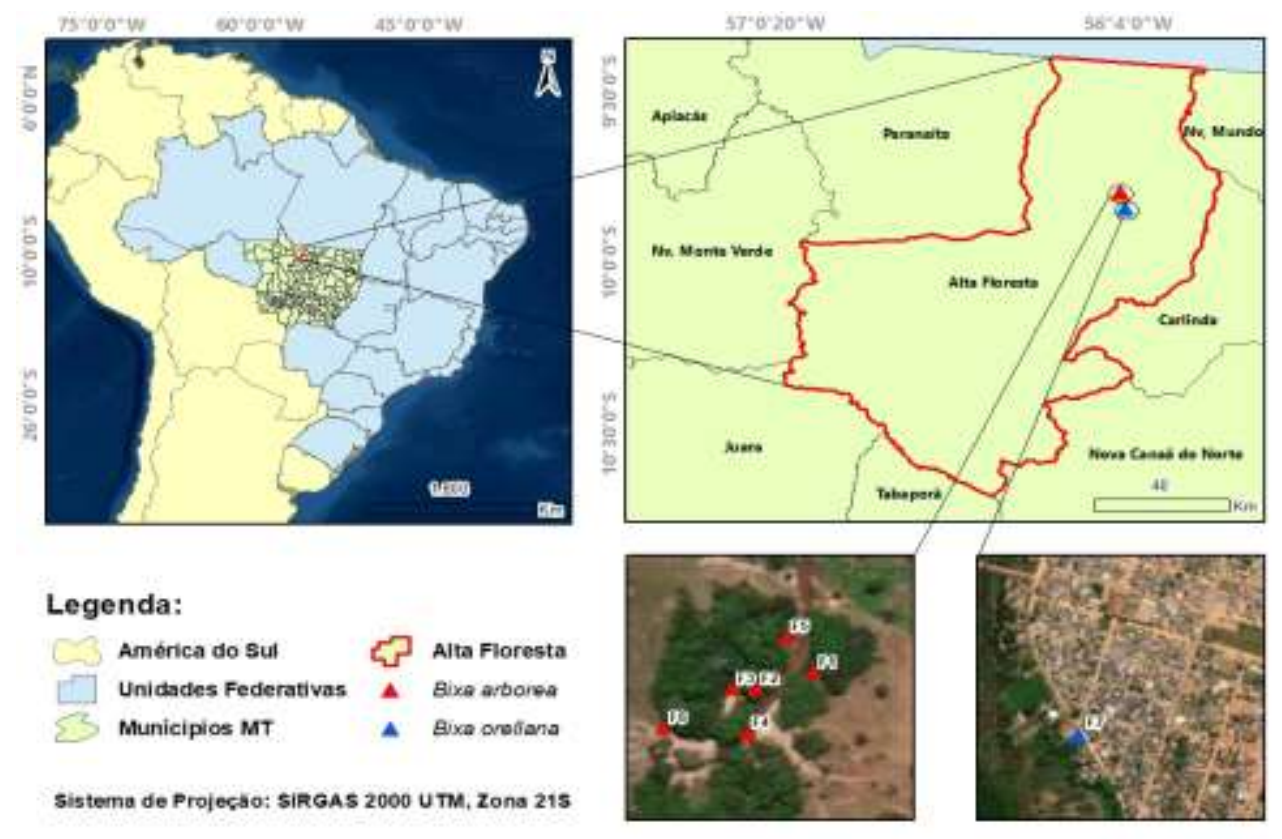

Fonte: Poletto.

As coletas dos fenótipos foram realizadas mediante a retirada de ramos férteis e herborizados de acordo com técnicas usuais (Fidalgo \& Bononi, 1989); as identificações foram confirmadas com base nas obras originais (Linnaeus, 1753; Huber, 1910) e informações disponíveis no site Flora do Brasil (Antar, 2020); os materiais foram preparados e incorporados na coleção do Herbário da Amazônia Meridional (HERBAM), da Universidade do Estado de Mato Grosso, Campus Universitário de Alta Floresta.

\subsection{Estudo morfológico dos fenótipos de Bixa}

As diagnoses morfológicas de B. arborea e B. orellana foram realizadas no Laboratório de Morfologia Vegetal, localizado nas dependências do HERBAM, entre março e setembro de 2020. Foram realizadas a partir de informações 
qualitativas e quantitativas dos espécimes, fazendo uso de materiais desidratados (partes vegetativas e carpológicas) e reidratados (flores) com o uso de régua, papel milimetrado e um estereomicroscópio (Figura 2). A terminologia foi baseada em Radford et al. (1974) e Barroso et al. (1999); para a realização das ilustrações, imagens dos caracteres diagnósticos dos espécimes foram selecionados e ilustrados por especialista na cidade de Viçosa, Estado de Minas Gerais.

Figura 2. Início da análise de caracterização morfológica dos fenótipos de B. arborea e B. orellana no HERBAM.

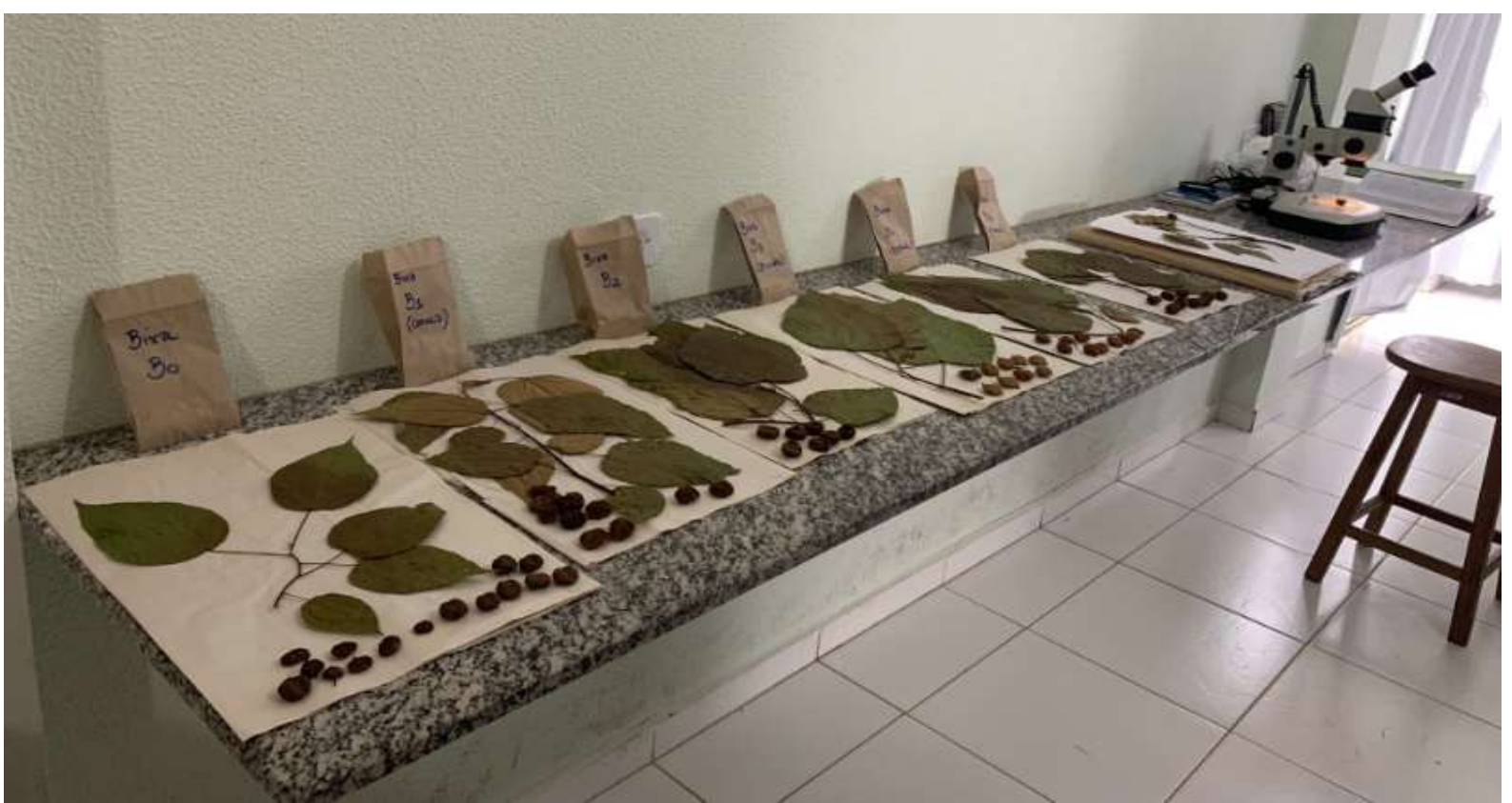

Fonte: Furini.

\section{Resultados}

O estudo morfológico de sete fenótipos de Bixa arborea e Bixa orelana em Alta Floresta, Mato Grosso, apresenta várias características utilizadas na separação entre eles, como o tipo da base do limbo foliar, número de estame, formato e comprimento do ápice do fruto, presença ou ausência de espinho no fruto, e comprimento e flexibilidade do espinho, conforme apresentados na chave de identificação a seguir.

\section{Chave para identificação de fenótipos de Bixa arborea e Bixa orellana em Alta Floresta, Mato Grosso}

1. Frutos totalmente cobertos por espinhos, 4-9,6 mm compr., flexíveis Bixa orellana

1'. Frutos papilosos ou parcialmente cobertos por espinhos, $0,1-1,8 \mathrm{~mm}$ compr., não flexíveis Bixa arborea

2. Frutos com ápice mucronatiforme longo, $3-6 \mathrm{~mm}$ compr. Bixa arborea fenótipo 4

2'. Frutos com ápice mucronatiforme curto, $0,8-2,8 \mathrm{~mm}$ compr., raramente truncado

3. Frutos com espinhos evidentes ao longo das faces, espinhos maiores 1,3-2,5 $\mathrm{mm}$ compr.

4. Folhas com base truncada; frutos $2,6-3,2 \times 1,8-2,7 \mathrm{~cm}$, elípticos raramente obovados Bixa arborea fenótipo 5

4'. Folhas com base cordada; frutos 2,4-3,3 $\times 2,4-2,9 \mathrm{~cm}$, transversalmente elípticos Bixa arborea fenótipo 6

3'. Frutos lisos ou raramente com espinhos vestigiais esparsos, quando presentes, $0,1-0,5 \mathrm{~mm}$ compr.

5. Flores com 203-300 estames; frutos curtamente elípticos a transversalmente elípticos

6. Flores com 230-285 estames; frutos curtamente elípticos Bixa arborea fenótipo 1 
6'. Flores com 203-300 estames Bixa arborea fenótipo 2

5'. Flores com 397-460 estames; frutos curtamente oblongos Bixa arborea fenótipo 3

\subsection{Bixa arborea Huber, Bol. Mus. Goeldi Hist. Nat. Ethnogr. 6: 87. 1910.}

Arbustos a árvores, 3-6,5 m alt.; ramos jovens lepidotos, nectários extraflorais nos nós, elevados, sésseis, planos, obovados, circulares a semicirculares. Estípulas caducas. Folhas alternas, simples, pecíolo cilíndrico, lâmina ovada, margens sinuosas a levemente sinuosas. Inflorescências em panículas terminais; brácteas caducas presentes nas ramificações das inflorescências; pedicelo geralmente com cinco nectários extraflorais abaixo do cálice, lenticulares; flores pentâmeras, actinomorfas, dialissépalas e dialipétalas; estames livres, anteras rimosas; ovário unilocular, bicarpelar, óvulos com placentação parietal, estilete terminal, estigma lobado. Fruto tipo cápsula loculicida, bivalvar, papiloso ou curtamente equinado, espinhos não flexíveis quando presentes, indeiscente. Sementes numerosas, glabras, obtriangulares, testa carnosa, alaranjada, arilo branco, discreto.

\subsubsection{Bixa arborea fenótipo 1.}

Figura 3 A-C

Árvore $6 \mathrm{~m}$ alt. Estípulas 9-10 mm compr., lanceoladas. Pecíolo 3,5-7,5 cm compr., glabrescente a esparsamente lepidoto, lâmina 9-19 × 6-11,2 cm, base cordada, ápice cuspidado a caudado, face adaxial glabra e face abaxial esparsamente lepidota. Brácteas 5-6 × 3,5-4 mm, oblongas, caducas; pedicelo 6-8 mm compr.; sépalas 7,5-8 x 8-9 mm, oblatas, esparsamente lepidotas, cimbiformes, pétalas 22-27 x 13-15 mm, obovadas, glabras, pontos translúcidos e rajas alaranjadas presentes; 230-285 estames, filetes 14-18 mm compr., anteras 1,3-1,8 mm compr.; ovário 2,8-3 x 2,7-3 mm, ovado, espinhos presentes, estilete 15-16 mm compr., estigma 0,3-0,5 mm compr. Frutos 1,6-3 × 1,8-2,8 cm, curtamente elípticos, base aguda, ápice mucronatiforme curto, 1-1,7 mm compr., lisos, raramente com espinhos curtos, 0,1-0,5 mm compr., linhas transversais evidentes; (1-)3-13 sementes, 4,2-5 x 2,3-3,8 mm, obtriangular, sarcotesta rugosa, caramelo. Material testemunho: J. M. Fernandes et al. 1554 (HERBAM), T. Furini et al. 04 (HERBAM).

O fenótipo 1 foi coletado a 10 metros da margem do rio e cerca de 6 metros de altitude em relação ao nível do rio (239 metros de altitude em relação ao nível do mar), associado a um solo arenoso de encosta, parcialmente úmido (Figura 4).

\subsubsection{Bixa arborea fenótipo 2.}

Figura 3 D-E

Árvore $4 \mathrm{~m}$ alt. Estípulas ca. 13 mm compr., lanceoladas. Pecíolo 2,3-6,5cm compr., lâmina 12-21,3 × 4-10,3 cm, base levemente cordada a truncada, ápice cuspidado a caudado, face adaxial glabra, face abaxial lepidota. Brácteas 4-6 x 3,5-4 mm oblongas, caducas; sépalas 8,5-9 × 8-9 mm, oblatas a circulares, lepidotas, pontos translúcidos alaranjados no ápice, pétalas 26-30 x 16-20 mm, obovadas, glabras, pontos translúcidos e rajas alaranjadas presentes; 203-300 estames, filetes 15$18 \mathrm{~mm}$ compr., anteras 1,5-2 mm compr.; ovário 2,5-3 x 2-2,1 mm, ovado, espinhos presentes, estilete 16-17 mm compr., estigma 0,4-0,5 mm compr. Frutos 2,2-2,8 × 2,5-3,2 cm, transversalmente elípticos, base obtusa, ápice mucronatiforme curto, 1-2,8 mm compr., lisos, raramente com espinhos curtos, $0,1-0,5 \mathrm{~mm}$ compr., linhas transversais evidentes; $5-10$ sementes, 4,5-5,0 $\times$ 4,0-4,8 mm, obtriangular, sarcotesta rugosa, caramelo. Material testemunho: J. M. Fernandes et al. 1556 (HERBAM), T. Furini et al. 05 (HERBAM).

O fenótipo 2 foi coletado as margens do rio com cerca de 1 metro de altitude em relação ao nível do rio. Está localizado em uma área periodicamente inundada com solo arenoso (Figura 4). 


\subsubsection{Bixa arborea fenótipo 3.}

\section{Figura 3 F-I}

Árvore 6,5 m alt. Estípulas ca. 15 mm compr., lanceoladas. Pecíolo 4,0-7,5 cm compr., lâmina 12,6-24 × 8,7-15 cm, base cordada, ápice curtamente cuspidado, face adaxial glabra, face abaxial lepidota. Brácteas 4,8 x 2,5 mm amplo elípticas, caducas; sépalas 8,5-9 x 5,5-8 mm, amplo elípticas, raramente circulares, lepidotas, pontos translúcidos alaranjados no ápice; pétalas 15-29 x 8-14 mm, obovadas, glabras, pontos translúcidos e rajas alaranjadas presentes; 397-460 estames, filetes 14-16 cm compr., anteras 1,1-1,7 mm compr.; ovário 3-3,2 x 2,8-3 mm, ovado, espinhos presentes, estilete 15-16,8 mm compr., estigma 0,2-0,6 mm compr. Frutos 2,6-3,5 × 1,8-2,3 cm, curtamente oblongos, base truncada a levemente aguda, ápice mucronatiforme curto, $0,8-2 \mathrm{~mm}$ compr., lisos, raramente com espinhos curtos, $0,1-0,5 \mathrm{~mm}$ compr., linhas transversais evidentes; 3-8 sementes, 5-5,2 $\times$ 4,2-4,5 mm, obtriangular, sarcotesta rugosa, caramelo. Material testemunho: J. M. Fernandes et al. 1557 (HERBAM), T. Furini et al. 06 (HERBAM).

O fenótipo 3 foi coletado em uma área com solo arenoso, próximo à margem do rio com cerca de 4 metros de altitude em relação ao nível do rio (Figura 4).

\subsubsection{Bixa arborea fenótipo 4.}

Figura 5 A-B

Arbusto $4 \mathrm{~m}$ alt. Estípulas $24 \mathrm{~mm}$ compr., lanceoladas. Pecíolo 9-11 cm compr., lâmina 28,5-30 × 17,6-20 cm, base truncada a cordada, ápice cuspidado, faces adaxial glabra e abaxial lepidota. Flores não observadas. Frutos 2,7-4 × 2,4-3 cm, amplo elípticos, linhas transversais evidentes, espinhos curtos e esparsos, base aguda, ápice mucronatiforme longo, 3-6 mm compr., espinhos 0,8-2 mm compr.; 6-15 sementes, 3,2-5,2 × 2,7-3,5 mm, obtriangular, sarcotesta rugosa, caramelo escuro. Material testemunho: J. M. Fernandes et al. 1560 (HERBAM).

O fenótipo 4 foi encontrado nas margens do rio, em uma área com solo periodicamente inundado, a 0,5 metro de altitude em relação ao nível do rio (Figura 4). Observa-se que o fenótipo 4 está localizado na mesma altitude que o fenótipo 5 , mas o primeiro apresenta ápice mucronatiforme longo entre 3 a $6 \mathrm{~mm}$ compr., enquanto que o segundo possui ápice mucronatiforme curto entre 1,0 a 2,0 mm compr. 
Research, Society and Development, v. 10, n. 8, e54110817706, 2021

(CC BY 4.0) | ISSN 2525-3409 | DOI: http://dx.doi.org/10.33448/rsd-v10i8.17706

Figura 3. Bixa arborea fenótipo 1 - A. ramo com folhas, B. fruto, C. semente; Bixa arborea fenótipo 2 - D. folhas, E. fruto; Bixa arborea fenótipo 3 - F. folha, G. inflorescência, H. gineceu, I. fruto.

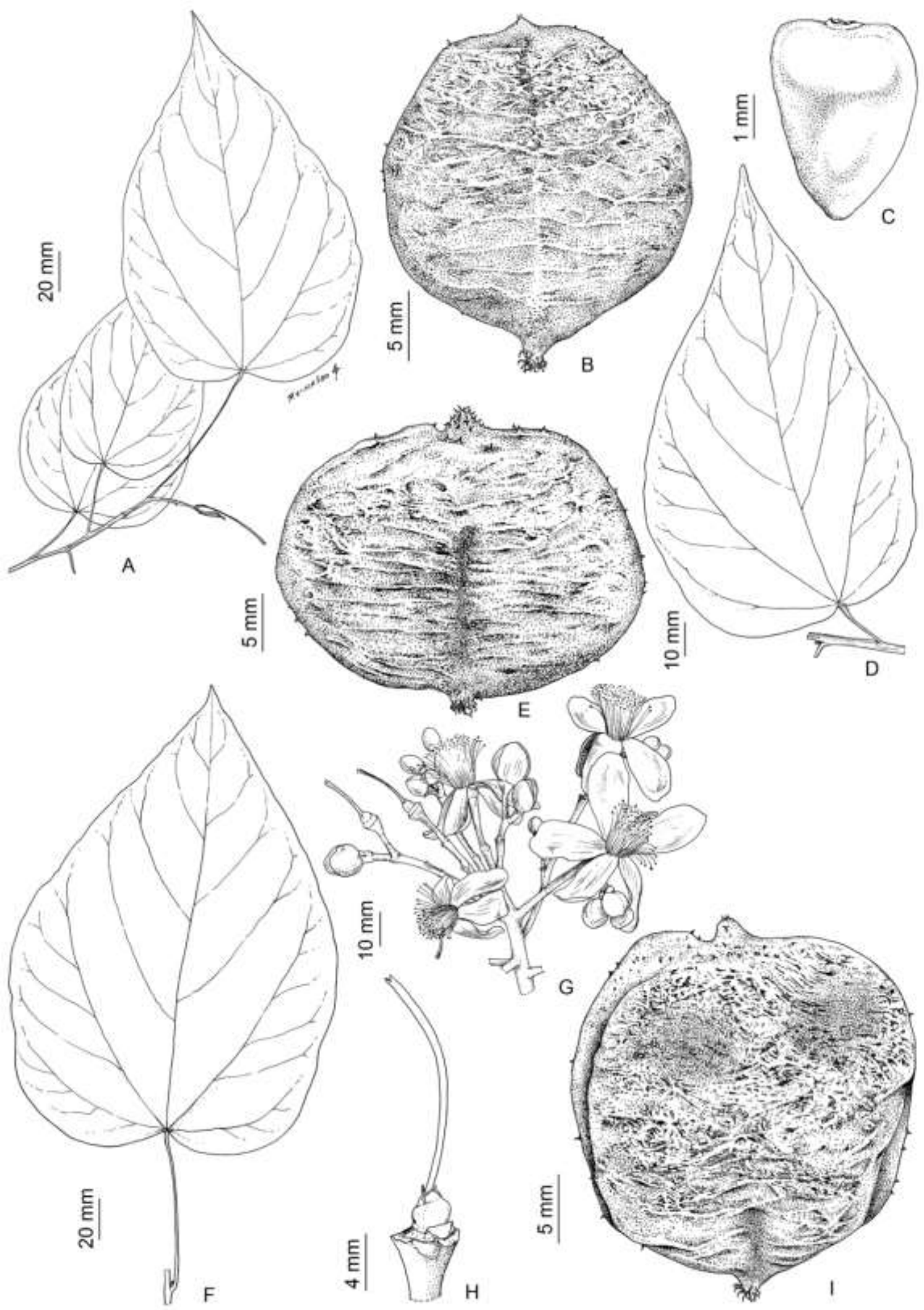

Fonte: Pinto, R. A. 


\subsubsection{Bixa arborea fenótipo 5.}

Figura 5 C-D

Arbusto $5 \mathrm{~m}$ alt. Estípulas $15 \mathrm{~mm}$. Folhas alternas, pecíolo 4,7-9 cm compr., lepidoto, lâmina 20,6-26,3 × 12,2-15,2 $\mathrm{cm}$, base truncada, ápice cuspidado, face adaxial glabra, face abaxial lepidota. Flores não observadas. Frutos 2,6-3,2 $\times 1,8-2,7$ $\mathrm{cm}$, elípticos, raramente obovados, base aguda, ápice mucronatiforme curto, 1,0-2,0 mm compr., raramente truncado, espinhos maiores $0,3-1,8 \mathrm{~mm}$ compr., linhas transversais evidentes; 4-13 sementes, 5,0-5,3 × 3,8-5,1 mm obtriangular, sarcotesta rugosa, caramelo. Material testemunho: J. M. Fernandes et al. 1558 (HERBAM).

O fenótipo 5 foi encontrado as margens do rio, em solo argiloso e submetido a frequente inundação, com altitude de 0,5 metro ao nível do rio (Figura 4).

\subsubsection{Bixa arborea fenótipo 6.}

Figura 5 E-F.

Árvore $3 \mathrm{~m}$ alt. Estípulas não observadas. Pecíolo 5,0-6,5 cm compr., lepidoto, lâmina 15,8-16,3 × 10,5-11,3 cm, base levemente cordada a truncada, ápice agudo a cuspidado, face adaxial glabra, face abaxial lepidota. Brácteas não observadas; sépalas 8-9 × 6-8 mm, amplo elípticas a circulares, lepidotas, pontos translúcidos alaranjados no ápice; pétalas 24-28 x 12-15 mm, obovadas, glabras, pontos translúcidos e rajas alaranjadas presentes; 295-339 estames, filetes 15-18 mm compr., anteras 1,3-1,7 mm compr.; ovário 3-3,3 x $3 \mathrm{~mm}$, romboide, espinhos presentes, estilete 17-18,5 mm compr., estigma 0,8-0,1 mm compr. Frutos 2,4-3,3 × 2,4-2,9 cm, transversalmente elípticos, base aguda, ápice mucronatiforme curto, 1,0-1,5 mm compr., espinhos maiores 1,3-2,5 mm compr., linhas transversais evidentes; 6-12 sementes, 4,5-5 × 3,5-3,8 mm, obtriangulares, sarcotesta rugosa, caramelo. Material testemunho: J. M. Fernandes 1559 (HERBAM), T. Furini et al. 07 (HERBAM).

O fenótipo 6 está localizado a cerca de 30 metros de distância da margem do rio e cerca de 8 metros de altitude em relação ao nível do rio. Está localizado na borda do fragmento florestal, em um solo arenoso e parcialmente úmido (Figura 4).

\subsection{Bixa orellana L., Sp. Pl. 1: 512. 1753.}

Figura 6 A-E.

Árvore $4 \mathrm{~m}$ al.; ramos jovens cilíndricos, ferrugíneos, lepidotos; estípulas 2,5-3 mm compr., estreitamente triangulares, caducas. Folhas simples, alternas, pecíolo $2-7 \mathrm{~cm}$ compr., lâmina 6,5-13 × 3,5-8,5 cm, cordiforme, base truncada, ápice caldado, raramente cuspidado, faces adaxial e abaxial esparsamente lepidotas, tricomas glandulares não observados. Inflorescência paniculada, terminal; 2 brácteas, $0,9-1 \times 0,3-0,5 \mathrm{~cm}$, cimbiformes, caducas, com um nectário lenticular próximo à base de cada uma; flores pediceladas, pedicelo 6-8 mm compr. Com 5 nectários terminais, conspícuos; 5 sépalas, 1-1,1 × 1,1-1,3 cm, oblatas, cimbiformes, livres, esparsamente lepidotas externamente, esverdeadas; 5 pétalas, 2,52,9 × 1,3-1,9 cm, obovadas, irregulares, livres, glabras, lilases; androceu ca. 390 estames, livres, lilases, filetes 1,3-1,4 cm compr., anteras 1-1,2 mm compr., rimosas; ovário 5-6 × 3-4 mm, ovado, unilocular, bicarpelar, estrigoso, estilete 1,4-1,5 cm compr., estigma infundibuliforme compresso, bífido. Fruto tipo cápsula loculicida, 3,5-4 × 3-3,3 cm, ovado, não comprimido, base obtusa, ápice mucronatiforme, epicarpo verde ou vermelho, equinado, espinhos flexíveis, 4-9,6 mm compr.; 40 sementes 4,9-5 x 4-4,3 mm, obdeltada, sarcotesta avermelhada, arilo branco na base. Material testemunho: T. Furini \& C. E. Felito 01 02 (HERBAM), T. Furini \& C. E. Felito 03 (HERBAM).

Em Alta Floresta foi coletada em um quintal urbano, cultivada para produção de sementes usadas no preparo de pigmento para consumo familiar, a cerca de 263 metros de altitude em relação ao nível do mar (Figura 7). 
Research, Society and Development, v. 10, n. 8, e54110817706, 2021

(CC BY 4.0) | ISSN 2525-3409 | DOI: http://dx.doi.org/10.33448/rsd-v10i8.17706

Figura 4. Informações ecológicas sobre os locais de ocorrência dos seis fenótipos de Bixa arborea em Alta Floresta (MT): A) $B$. arborea fenótipo 1; B) B. arborea fenótipo 2; C) B. arborea fenótipo 3; D) B. arborea fenótipo 4; E) B. arborea fenótipo 5; F) B. arborea fenótipo 6 .
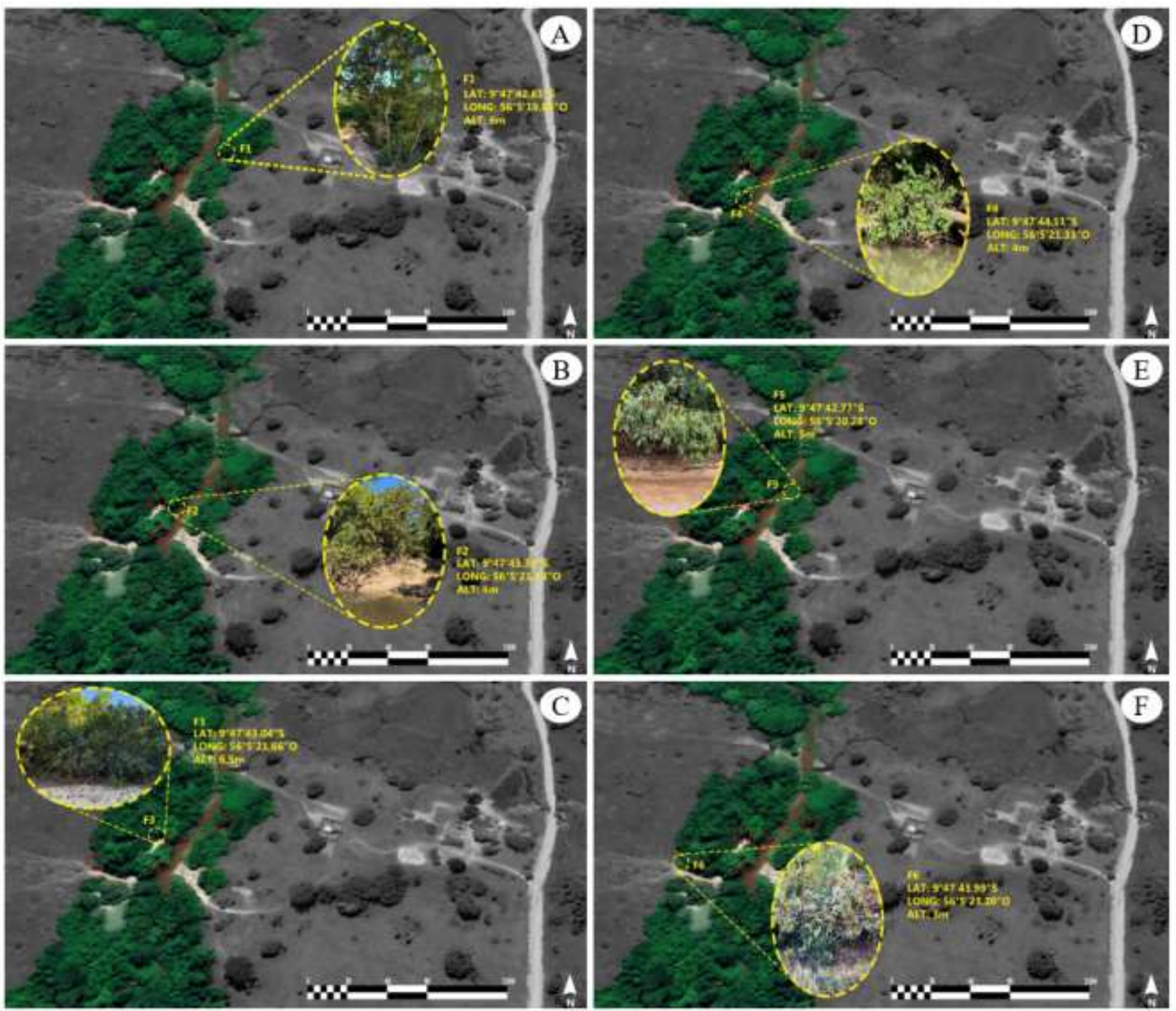

Fonte: Furini. 
Research, Society and Development, v. 10, n. 8, e54110817706, 2021

(CC BY 4.0) | ISSN 2525-3409 | DOI: http://dx.doi.org/10.33448/rsd-v10i8.17706

Figura 5. Bixa arborea fenótipo 4 - A. ramo com folhas, B. fruto; Bixa arborea fenótipo 5 - C. folha, D. fruto; Bixa arborea fenótipo 6 - E. folhas, F. fruto.

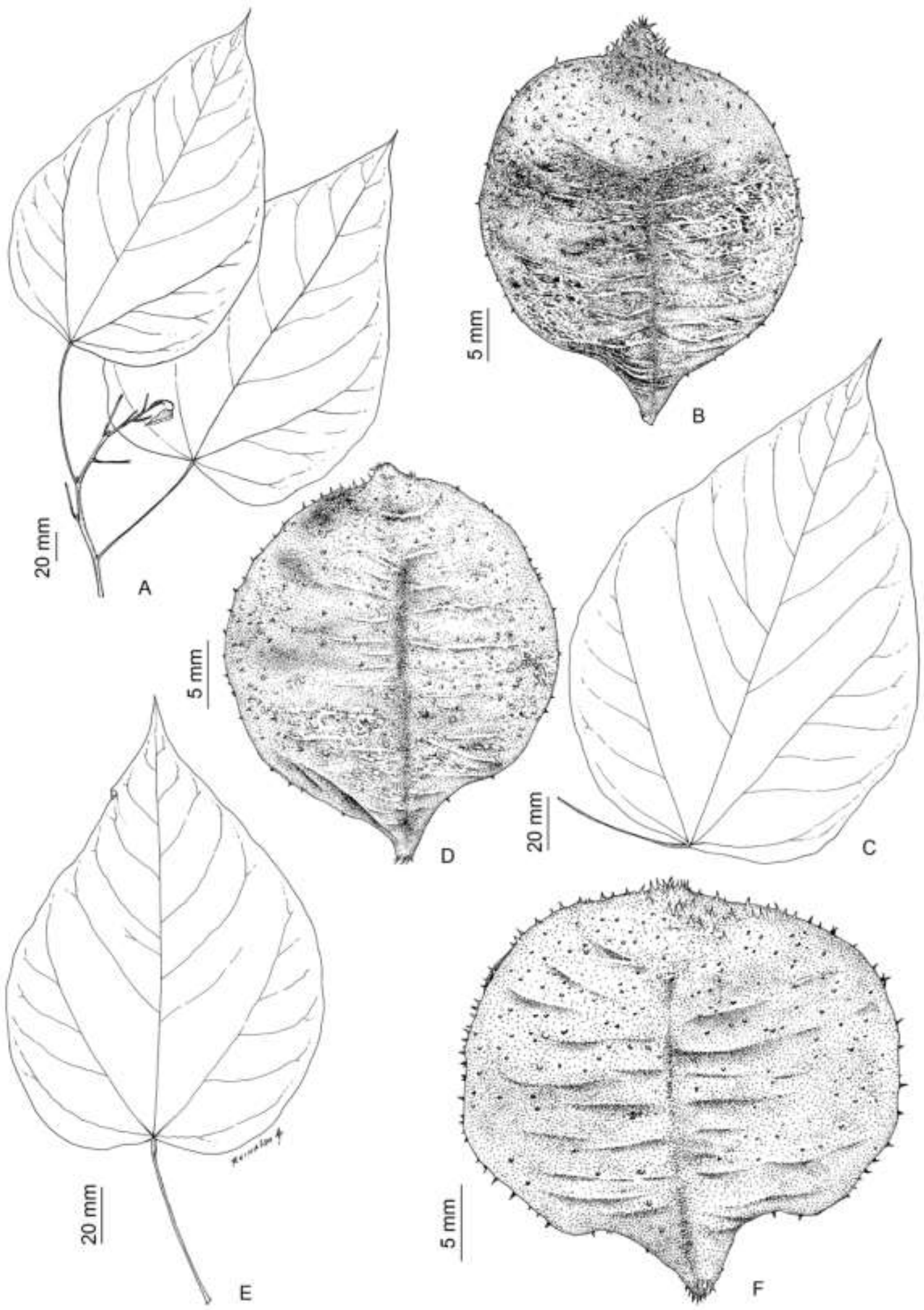

Fonte: Pinto, R. A. 
Figura 6. Bixa orellana - A. ramo com folhas, B. Inflorescência, C. Gineceu, D. frutos, E. semente.

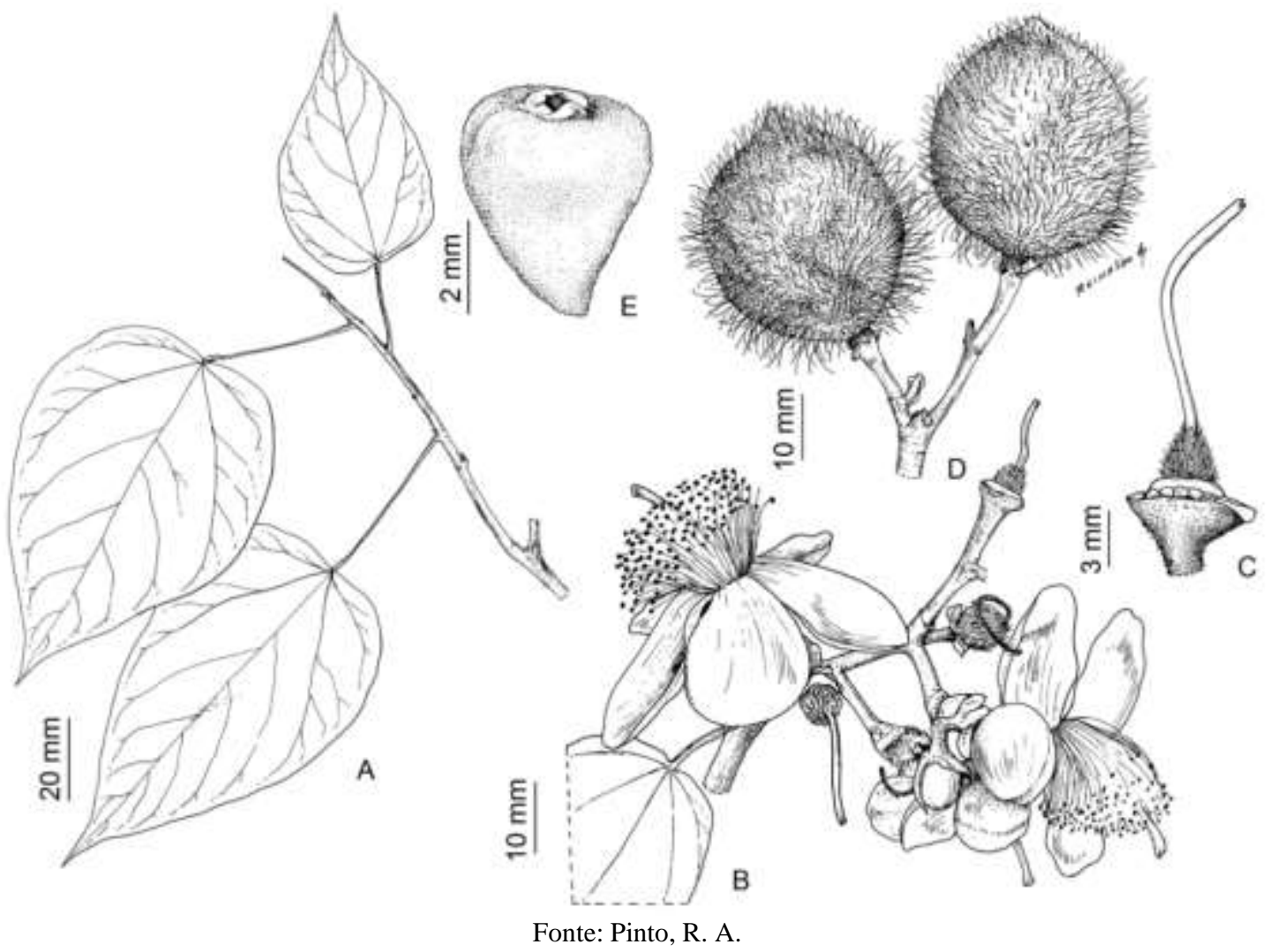

Figura 7. Área de localização de Bixa orellana fenótipo 7, Alta Floresta - MT.

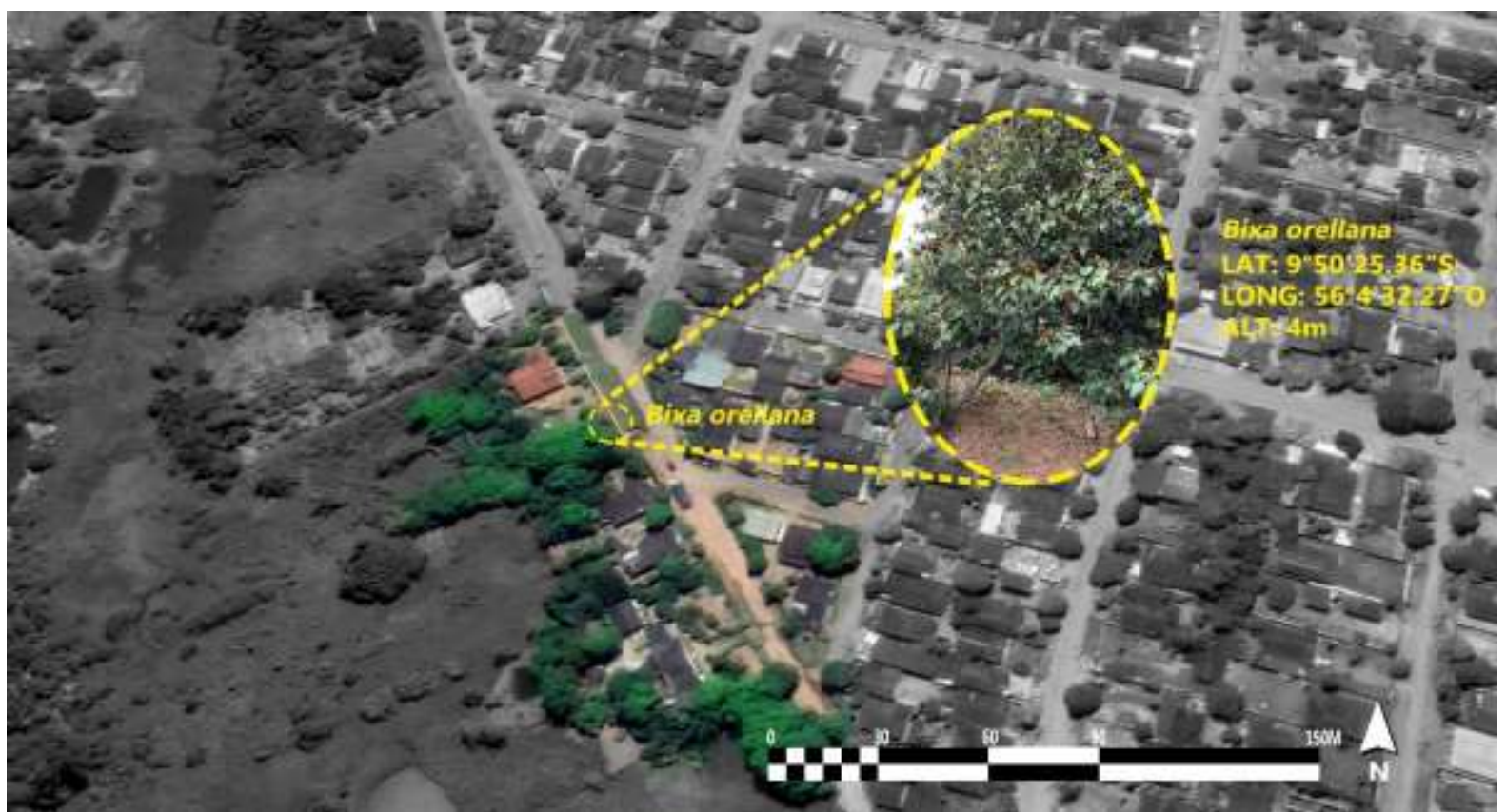

Fonte: Furini, T.

\section{Discussão}

Bixa arborea assemelha-se à Bixa orellana quanto a características vegetativas e florais (folha, cálice, corola e androceu), mas facilmente diferenciada pelos frutos comprimidos e esparsamente papilosos (Huber, 1910), enquanto que a 
segunda espécie possui frutos não comprimidos, equinados e com espinhos flexíveis.

No presente trabalho, foi possível verificar que os frutos de Bixa arborea são raramente papilosos (tubérculos diminutos), predominando a presença de espinhos curtos, que variam desde 0,1 até 2,5 milímetros de comprimento, sempre rígidos (não flexíveis), o que pode ser enquadrado como frutos papilosos a curtamente equinados. Informações não encontradas até agora na literatura de taxonomia (Huber, 1910; Baer, 1976; Poppendieck, 1981; Christenhusz, 2012), nem no site da Flora do Brasil (Antar, 2020).

Também foi proposto para os frutos das duas espécies o uso do termo "mucronatiforme" para caracterização do ápice, como uma adaptação à terminologia proposta por Radford et al. (1974), como sendo aquele ápice com a proporção 3:1 (comprimento x largura), reto e rígido, útil na distinção dos fenótipos estudados no município de Alta Floresta (MT).

Fazendo uso da morfologia vegetal foi possível distinguir os seis fenótipos de Bixa arborea por meio de uma chave de identificação, com o uso da forma da base do limbo foliar, número de estames, formato e comprimento do ápice do fruto, presença ou ausência de espinhos nos frutos, comprimento e rigidez dos espinhos. A importância da morfologia vegetal também pode ser observada no trabalho de Suassuna et al. (2016), que realizaram a caracterização de variedades de amendoim (Arachis hypogaea L., Fabaceae) provenientes do Parque Nacional do Xingu, estado de Mato Grosso, onde diferenciaram 14 variedades cultivadas pelos índios Kayabi, destacando-se o hábito de crescimento, altura e pigmentação da haste, indumento foliar, cor do estandarte e do ginóforo, comprimento do fruto, padrão de constrição do fruto e tipo de ápice do fruto, além do comprimento e cor da semente.

A espécie Bixa arborea é nativa no México, região Centroamérica, Caribe e América do Sul tropical (Richter \& Dallwitz, 2000). No Brasil, ocorre nos estados do Acre, Amazonas, Pará, Rondônia, Tocantins (Norte), Bahia (Nordeste), Mato Grosso (Centro-Oeste), Espírito Santo, Rio de Janeiro e São Paulo (Sudeste), em Floresta Ciliar, Matas de Galeria, Floresta de Terra Firme e Floresta Ombrófila, nos domínios fitogeográficos da Amazônico e da Mata Atlântica (Lleras, 2012; Antar, 2020). No Estado de Mato Grosso, a espécie é conhecida popularmente como urucu-da-mata, e ocorre em Floresta Ombrófila Aberta, Floresta Ombrófila Densa, Formação Savânica, Floresta de Galeria e Floresta Ciliar (Borges et al., 2014).

Em Alta Floresta foi coletada em uma área de Floresta Ciliar, caracterizada como uma monodominância devido à densidade de indivíduos na área, além de indivíduos esparsos em alguns trechos da propriedade. Segundo Lleras (2012), estudos fitossociológicos indicam que a espécie é bastante frequente nas áreas de ocorrência, sendo encontrado até 266 indivíduos por hectare. Em alta densidade das populações de B. arborea há uma garantia de uma alta variabilidade fenotípica, pois quanto maior a população, maior é o fluxo gênico e a variabilidade genética intrapopulacional (Kageyama \& Gandara, 1998; Primack \& Rodrigues, 2001; Newbold et al., 2015). No entanto, populações pequenas e isoladas geralmente estão sujeitas à perda da variabilidade genética devido ao aumento da endogamia e deriva genética (Primack \& Rodrigues, 2001; Cushman et al., 2016) que não é o caso das populações estudadas em Alta Floresta.

Bixa arborea é uma espécie que ocorre em ambientes próximos a corpos d'água, geralmente associados à vegetação ripária ou ciliar (Silva et al., 2017). A população de B. arborea amostrada apresentou uma alta densidade de indivíduos, o que pode ser influenciado pela relação, solo, água e planta, pois diversos estudos mostram que monodominância e a alta abundância de espécies vegetais em determinados ambientes se deve a essa relação (Van Der Valk, 1981; Arieira \& Cunha, 2006).

Bixa orellana é caracterizada pela presença de glândulas conspícuas e esverdeadas no ápice do pedicelo, frutos equinados, deiscentes e glabros, e pelas sementes com sarcotesta vermelho-alaranjada (Eichler, 1871; Christenhusz, 2012), além de apresentar frutos ovados.

Possui distribuição neotropical, com distribuição desde o México até a Argentina (Christenhusz, 2012). No Brasil, ocorre em todos os estados e no Distrito Federal, nos domínios fitogeográficos da Amazônia, Cerrado e Mata Atlântica, nos 
mais diversos tipos de vegetação (BFG, 2018; Antar, 2020). Borges et al. (2014) não apresentam B. orellana na obra "Flora Arbórea de Mato Grosso: tipologias vegetais e suas espécies", provavelmente por ser uma espécie com domesticação antiga na América do Sul.

Após a análise da coleção do HERBAM, verificou-se que nenhum espécime de B. orellana depositado na coleção foi oriundo de áreas nativas da região de Alta Floresta. Segundo Moreira et al. (2015), provavelmente o urucum selvagem (Bixa urucurana Willd.) seja o ancestral do urucum cultivado (Bixa orellana), que possui frutos indeiscentes, indicando alterações na deiscência durante a sua domesticação, também são menores e com pouco pigmento (não usados como fonte de corante), enquanto que o urucum cultivado possui frutos deiscentes, muitas sementes e pigmento em abundância. Atualmente, $B$. urucurana é considerada como sinônimo de B. orellana (Antar, 2020).

De acordo com Dequigiovanni et al. (2018), em estudo da diversidade genética de $B$. orellana, incluindo amostras selvagens e cultivadas, verificaram que é mais elevada para as populações selvagens quando comparadas às populações cultivadas, além disso, indicam um sistema de cruzamento misto para a espécie entre populações selvagens e cultivadas. $\mathrm{O}$ estudo mostrou que o distanciamento geográfico das populações de B. orellana proporciona uma maior variabilidade genética a espécie. Isso contribui para uma diversificação fenotípica intrapopulacional, o que se deve sobretudo, a forma de reprodução da espécie, que apresenta alta taxa de endogamia (Dequigiovanni et al., 2018).

Bixa orellana embora seja muito utilizada comercialmente, é facilmente encontrada de forma nativa, sobretudo em fragmentos antropizados (Dequigiovanni et al., 2017). Essa espécie é muito utilizada por grande parte da população de toda a América Latina e vem sendo selecionada e cultivada há muito tempo, gerando novos cultivares (Clement et al., 2010; Moreira et al., 2015): Em um estudo Barbosa-Filho et al. (1998) relataram 4 variedades de B. orellana que eram cultivadas na Paraíba: Casca verde", "Casca vermelha", Bico de calango" e "Grão preto". A Embrapa buscando o melhoramento genético e o aumento da qualidade de bixina presente nas sementes de B. orellana, desenvolveu dois cultivares Embrapa 36 e Embrapa 37 (Poltronieri et al., 2001). No Brasil são geralmente utilizados em plantações os cultivares Piave Vermelha, Wagner, Peruana Pará, Bico de Pato, Peruana Paulista e Piave Verde Limão (Poltroniere et al., 2001; Franco et al., 2008; Ferreira-Filho et al., 2018). As características reprodutivas, o isolamento geográfico e as influências ambientais, bem como a manipulação antrópica da espécie por anos tem garantido a diversidade e plasticidade fenotípica encontrada na espécie (Dequigiovanni et al., 2017; Dequigiovanni et al., 2018; Faria et al., 2019).

\section{Conclusão}

As duas espécies analisadas apresentaram muitas semelhanças morfológicas entre si, principalmente quanto a caracteres vegetativos e florais, contudo, diferiram em relação aos frutos. Bixa arborea apresenta frutos comprimidos, base aguda, esparsamente papilhosos ou com espinhos não flexíveis (rígidos), enquanto que Bixa orellana apresenta frutos não comprimidos, base obtusa e equinados com espinhos flexíveis.

Os fenótipos de B. arborea analisados em uma única população apresentaram diferenças quanto ao tipo de hábito, tipo da base foliar, número de estames, tamanho e formato dos frutos, comprimento dos ápices dos frutos, presença de papilas ou de espinhos nos frutos e comprimento dos espinhos nos frutos. Para as sementes não foram encontradas diferenças morfológicas entre os fenótipos.

\section{Agradecimentos}

À Universidade do Estado de Mato Grosso (UNEMAT) Carlos Alberto Reyes Maldonado; ao Programa de Programa de Pós-graduação em Genética e Melhoramento de Plantas (UNEMAT), pelo mestrado concedido a primeira autora; à 
Coordenadoria de Aperfeiçoamento de Pessoal de Nível Superior (CAPES), pela bolsa de estudo à primeira e quarta autoras; e, ao Herbário da Amazônia Meridional (HERBAM), pela espaço disponibilizado para execução de parte da pesquisa.

\section{Referências}

Alonso, J. (2004). Tratado de fitofármacos y nutracêuticos. Corpus.

Amaral, E. V. E. J. (2012). Caracterização morfológica e identificação taxonômica de espécies de Campomanesia Ruiz \& Pavon (Myrtaceae). Dissertação de Mestrado, Universidade Federal de Goiás, Jataí, GO, Brasil.

Antar, G. M. (2020). Bixaceae in Flora do Brasil 2020 em construção. Jardim Botânico do Rio de Janeiro. http://floradobrasil.jbrj.gov.br/reflora/floradobrasi 1/FB62

APG - Angiosperm phylogeny Group (2016). An update of the Angiosperm Phylogeny Group classification for the orders and families of flowering plants: APG IV. Botanical Journal of the Linnean Society, 181, 1-20.

Arieira, J., \& Cunha, C. N. (2006). Fitossociologia de uma floresta inundável monodominante de Vochysia divergens Pohl (Vochysiaceae), no Pantanal Norte, MT, Brasil. Acta Botanica Brasilica, 20 (3), 569-580. https://doi.org/10.1590/S0102-33062006000300007

Baer, D. F. (1976). Systematics of the genus Bixa and geography of the cultivated annatto tree. PhD Thesis, University of California, Los Angeles, United States of America.

Barbosa-Filho, J. M., Barbosa-Filho, J., Silva-Filho, R. N., Lira, B. F., Macêdo, R. O. L., Silva, M. S., Chaves, M. C. O., Souza, M. F. V., Cunha, E. V. L., \& Athayde-Filho, P. F. (1998). Teor de bixina em quatro variedades de Bixa orellana L. cultivadas na Paraíba. Revista brasileira de farmacognosia, 7-8 (1), 4147. https://doi.org/10.1590/S0102-695X1998000100005

Barroso, G., Morim, M. P., Peixoto, A. L., \& Ichasso, C. L. F. (1999). Frutos e sementes: morfologia aplicada à sistemática de dicotiledôneas. Viçosa: Imprensa Universitária.

BFG - The Brazil Flora Group (2018). Brazilian Flora 2020: Innovation and collaboration to meet Target 1 of the Global Strategy for Plant Conservation (GSPC). Rodriguésia, 69 (4), 1513-1527. https://doi.org/10.1590/2175-7860201869402

Borges, H. B. N., Silveira, E., \& Vendramim, L. N. (2014). Flora arbórea de Mato Grosso: tipologias vegetais e suas espécies. Entrelinhas.

Castro, C. B., Martins, C. S., Falesi, I. C., Nazare, R. F. R., Kato, O. H., Benchimol, R. L., \& Venturieri, M. M. (2009). A Cultura do Urucum. Brasília, Embrapa Informação Tecnológica.

Christenhusz, M. J. M. (2012). Bixaceae. In: Davidse, G., Sousa, M. \& Chater, A.O. Flora Mesoamericana. Cidade do Universidad Nacional Autónoma de México, México.

Clement, C. R., Cristo-Araújo, M., D’Eeckenbrugge, G. C., Alves-Pereira, A., \& Picanço-Rodrigues, D. (2010). Origin and domestication of native Amazonian crops. Diversity, 2 (1), 72-106. https://doi.org/10.3390/d2010072

Corrêa, M. P., \& Penna, L. (1984). Dicionário das plantas úteis do Brasil e das exóticas cultivadas. Rio de Janeiro: Instituto Brasileiro de Desenvolvimento Florestal, 6, 358-359. https://doi.org/10.1002/9781118525258.ch02

Cushman, S. A., Mcrae, B. H., \& Mcgarigal, K. (2016). Basics of Landscape Ecology: An Introduction to Landscapes and Population Processes for Landscape Geneticists. In: Balkenhol, N. et al., 191 Landscape Genetics: Concepts, Methods, Applications. Chichester: John Wiley \& Sons.

Demczuk J. R. B., \& Ribani, R. H. (2015). Atualidades sobre a química e a utilização do urucum (Bixa orellana L.). Revista Brasileira de Pesquisa em Alimentos, 6(1), 37-50. https://doi.org/10.14685/rebrapa.v6i1.144

Dequigiovanni, G., Ramos, S. L. F., Alves-Pereira, A., Fabri, E. G., Carvalho, P. R. N., Silva, M. G., Abdo, M. T. V. N., Martins, A. L. M., Clement, C. R., \& Veasey, E. A. (2017). Genetic diversity and structure in a major Brazilian annatto (Bixa orellana) germplasm bank revealed by microsatellites and phytochemical compounds. Genetic Resources and Crop Evolution, 64, 1775-1788. https://doi.org/10.1007/s10722-017-0535-z

Dequigiovanni, G., Ramos, S. L. F., Lopes, M. T. G., Clement, C. R., Rodrigues, D. P., Fabri, E. G., Zucchi, M. I., \& Veasey, E. A. (2018). New microsatellite loci for annatto (Bixa orellana), a source of natural dyes from Brazilian Amazonia. Crop Breeding and Applied Biotechnology, 18(1), 116-122. https://doi.org/10.1590/1984-70332018v18n1n18

Dias, N. O., Reboucas, T. N. H, São José, A. R., \& Amaral, C. L. F. (2017). Morpho-agronomic characterization and estimates of genetic parameters in annatto plant. Horticultura Brasileira, 35(2). https://doi.org/10.1590/S0102-053620170214

Eichler, A. G. (1871). Bixaceae. In: Martius, C. F. P., Eichler, A. G. (eds.). Flora brasiliensis. Lipsiae, Frid. Fleischer, 13 (1), $421-516$.

Faria, D. V., Correia, L. N. F., Souza, M. V. C., Ríos-Ríos, A. M., VitaL, C. E., Batista, D. S., Costa, M. G. C., \& Otoni, W. C. (2019). Irradiance and light quality affect two annatto (Bixa orellana L.) cultivars with contrasting bixin production. Journal of Photochemistry and Photobiology B: Biology. 197.

Fenner, M. (1993). Seed ecology. London: Chapman \& Hall. 
Ferraz, R. M., Ragassi, C. F., Heinrich, A. G., Lima, M. F., Peixoto, J. R., \& Reifschneider, F. J. B. (2016). Caracterização morfoagronômica preliminar de acessos de pimentas cumari. Horticultura Brasileira, 34(4), 498-506. https://doi.org/10.1590/S0102-053620160408

Ferreira-Filho, G. S. F. (2018). Cultivo de urucum sistema de produção. Rondônia: Emater.

Fidalgo, O., \& Bononi, V. L. R. (1989). Técnicas de coleta, preservação e herborização do material botânico. Instituto de Botânica.

Franco, C. F. O., Fabri, E. G., Barreiro Neto, M., Manfiolli, M. H., Harder, M. N. C., \& Rucker, N. C. A. (2008). Urucum: sistemas de produção para o Brasil. João Pessoa: EMEPA.

Franco, C. F. O., Silva, F. C. P., Cazé Filho, J., Barreiro Neto, M., José, A. R. S., Rebouças, T. N. H., \& Fontinélli, I. S. C. (2002). Urucueiro: Agronegócio de corantes naturais. João Pessoa: Embrapa.

Garcia, C. E. R., Bolognesi, V. J., Dias, J. F. G., Miguel, O. G., \& Costa, C. K. (2012). Carotenoides bixina e norbixina extraídos do urucum (Bixa orellana L.) como antioxidantes em produtos cárneos. Ciência Rural, 42(8), 1510-1517.

Huber, J. (1910). Novitates Florae Amazonicae. Boletim do Museu Paraense de História Natural e Ethnographia, 6(2), 60-90.

IBGE - Instituto brasileiro de geografia e estatística (2019). Cidades - Senso agropecuário. https://cidades.ibge.gov.br/brasil/pesquisa/24/76693

IBGE - Instituto brasileiro de geografia e estatística (2021). Cidades e Estados. https://www.ibge.gov.br/cidades-e-estados/mt/alta-floresta.html

Izidoro, M., Prates, A. R., Neves, C. S., Souza, E. P., Lossolli, N. A. B., \& Bonfim, F. P. G. (2021). Functional and organoleptic properties of condiment plants: Review. Research, Society and Development, 10(6), e2010614958. https://doi.org/10.33448/rsd-v10i6.14958.

Jesus, F. N., Machado, C. F., Souza, V. O., Matos, M. S. S., Silva, J. S., Ledo, C. A. S., \& Faleiro, F. G. (2014). Caracterização morfoagronômica de acessos da coleção de maracujá da Embrapa Mandioca e Fruticultura. Boletim de Pesquisa e Desenvolvimento, 61, 1-26.

Kageyama, P. Y., \& Gandara, F. B. (1998). Indicadores de sustentabilidade de florestas naturais. Série Técnica IPEF, 12(31), 79-84.

Linnaeus, C. (1753). Species Plantarum. Vol. 1. Imprensis Laurentii Salvii: Holmiae.

Lleras, E. (2012). Bixa arborea in Bixa (Bixaceae) in Lista de Espécies da Flora do Brasil. http://floradobrasil.jbrj.gov.br/2012/FB005744

Lorenzi, H., \& Matos, F. J. A. (2008). Plantas medicinais no Brasil: nativas e exóticas. Nova Odessa: Instituto Plantarum.

Machado, P. D. S. (2015) Caracterização do Uxi (Endopleura uchi) em três estádios de desenvolvimento. Dissertação de mestrado, Universidade Federal de Lavras, Lavras, MG, Brasil.

Mantovani, N. C., Grando, M. F., Xavier, A., \& Otoni, V. C. (2013). Avaliação de genótipos de urucum (Bixa orellana L.) por meio da caracterização morfológica de frutos, produtividade de sementes e teor de bixina. Ciência Florestal, 23(2), 355-362. https://doi.org/10.5902/198050989281

Mercadante, A. Z., Steck, A., \& Pfander, H. (1997). Isolation and identification of new apocarotenoids from annatto (Bixa orellana) seeds. Journal of Agricultural and Food Chemistry, 45 (4), 1050-1054. https://doi.org/10.1021/jf960412k

Moreira, P. A., Lins, J., Dequigiovanni G., Veasey E., \& Clement C. R. (2015). The Domestication of Annatto (Bixa orellana) from Bixa urucurana in Amazonia. Economic Botany, 69(2), 127-135.

Moreira, V. S. (2013). Atividade antioxidante e caracterização físico-química de variedades de urucueiros in natura e encapsulado. Dissertação de Mestrado, Universidade Estadual do Sudoete da Bahia, Itapetinga, BA, Brasil.

Newbold, T., Hudson, L., Hill, S., Contu, S., Lysenko, I., Senior, R., Börger, L., Bennett, D., Choimes, A., Collen, B., Day, J., De Palma, A., Diaz, S., Echeverria-Londono, S., Edgar, M., Feldman, A., Garon, M., Harrison, M., Alhusseini, T., \& Purvis, A. (2015). Global effects of land use on local terrestrial biodiversity. Nature, 520, 45-50 (2015). https://doi.org/10.1038/nature14324

Oliveira, A. C. A. X., Silva, I. B., Manhàes-Rocha, D. A., \& Paumgartten, F. J. R. (2003). Induction of liver monooxigenases by anatto and bixin in females rats. Brazilian Journal of Medical and Biological Research, 36(1), 113-118.

Oliveira, A. C., Endringer, D. C., Amorim, L. A., Graças, L. B. M., \& Coelho, M. M. (2005). Effect of the extracts and fractions of Baccharis trimera and Syzygium cumini on glycaemia of diabetic and non-diabetic mice. Journal of Ethnopharmacology, 102, 465-469. https://doi.org/10.1016/j.jep.2005.06.025

Pillai, S., Soni, S., Dhulap, S., \& Hirwani, R. R. (2018). Pharmacological and cosmeceutical applications of Bixa orellana L.: a reviw of the cscientific and patent literature. Indian Journal of Natural Products and Resources, 9(4), 281-289.

PMAF - Prefeitura municipal de Alta Floresta MT (2021). Geografia. https://www.gp.srv.br/transparencia_altafloresta/servlet/inf_div_detalhe?12

Poltronieri, M. C., Martins, C. S., Rodrigues, J. E., Costa, M. R., \& Nazaré, R. F. R. (2001). Novas Cultivares de Urucum: Embrapa 36 e Embrapa 37. Embrapa Amazônia Oriental. Belém, 21.

Poppendieck, H. H. (1981). Cochlospermaceae. Flora Neotropica Monograph. 27 (s/n)1-33. https://doi.org/10.1590/2175-78602017683423

Primack, R. B., \& Rodrigues, E. (2001). Biologia da Conservação. Editora Planta. 
Research, Society and Development, v. 10, n. 8, e54110817706, 2021

(CC BY 4.0) | ISSN 2525-3409 | DOI: http://dx.doi.org/10.33448/rsd-v10i8.17706

Raddatz-Mota, D., Pérez-Flores, L. J., Carrari, F., Mendozaespinoza, J. A., León-Sánchez, F. D., Pinzón-López, L. L., Godoy-Hernández, G., \& RiveraCabrera, F. (2017). Achiote (Bixa orellana L.): a natural source of pigment and vitamin E. Journal of Food, Science and Technology, 54(6), 1729-1741. https://doi.org/10.1007/s13197-017-2579-7

Radford, A. E., Dickison, W. C., Massey, J. R., \& Bell, C. R. (1974). Vascular plant systematics. Harper \& Row.

Richter, H. G., \& Dallwitz, M. J. (2000). Commercial timbers: descriptions, illustrations, identification, and information retrieval. In English, French, German, Portuguese, and Spanish. Version: 9th April 2019. https://www.delta-intkey.com/

Rivera-Madrid, R., Aguilar-Espinosa, M., Cárdenas-Conejo, Y., \& Garza-Caligaris, L. E. (2016). Carotenoid derivates in Achiote (Bixa orellana) seeds: synthesis and health promoting properties. Frontiers in Plant Science, 7 (s/n). https://doi.org/10.3389/fpls.2016.01406

Sales, E. H., Rosa, P. V. S., Mafra, N. S. C., Soares, L. B. C., Duarte, R. V. S., Dias, A. A. S., Costa, A. T., Nunes, L. K. S., Sousa, T. L., Felizardo, M. G. A. C., Oliveira, J. P. M., \& Everton, G. O. (2020). Influence of drying on the biological potentials of Bixa orellana L. essential oil. Research, Society and Development, 9(8), e737986371. https://doi.org/10.33448/rsd-v9i8.6371.

Silva, S. B., Sousa, V., Santos, C., Mariano, D., \& Okumura, R. (2017). Levantamento florístico do componente arbustivo-arbóreo da vegetação ciliar de fragmento no rio Parauapebas. Revista Agroecossistemas, 9(1), 99-115. http://dx.doi.org/10.18542/ragros.v9i1.4780

Soares, V. L., Rodrigues, S. M., Oliveira, T. M., Queiroz, T. O., Lima, L. S., Hora Junior, B. T., Gramacho, K. P., Micheli, F., Cascardo, J. C. M., Otoni, W. C., Gesteira, A., \& Costa, M. G. C. (2011). Unraveling new genes associated with seed development and metabolism in Bixa orellana L. by expressed sequence tag (EST) analysis. Molecular Biology Reporter, 38 (2), 1329-1340. https://doi.org/10.1007/s11033-010-0234-8

Souza, V. C., \& Lorenzi, H. (2019). Botânica sistemática. Nova Odessa: Instituto Plantarum.

Stevens, P. F. (2021). Angiosperm Phylogeny Website. Version 14, July 2017 [and more or less continuously updated since]." will do. http://www.mobot.org/MOBOT/research/APweb/

Suassuna, T. M, Freitas, F. O., \& Matos, R. G. (2016). Caracterização de variedades de amendoim provenientes do Parque nacional do Xingu. In. Diálogos de saberes - relatos da Embrapa. Embrapa. https://doi.org/10.1016/j.bjp.2015.07.024

Van Der Valk, A. G. (1981). Succession in wetlands: a Gleasonian approach. Ecology, 62(3), 689-696. https://doi.org/10.2307/1937737

Zappi, D. C., Sasaki, D., Milliken, W., Piva, J., Henicka, G. S., Biggs, N., \& Frisby, S. (2011). Plantas vasculares da região do Parque Estadual Cristalino, norte de Mato Grosso, Brasil. Manaus, Acta Amazonica, 41(1), 29-38. https://doi.org/10.1590/S0044-59672011000100004 